\title{
CONCEPT OF A SYSTEM OF PLANT PROTECTION SUPPORT BASED ON THE ERP SYSTEM
}

\author{
Michal CUPIAL \\ University of Agriculture in Krakow, Faculty of Production and Power Engineering, POLAND \\ E-mail of corresponding author: michal.cupial@ur.krakow.pl
}

Keywords: IPM, plant protection products, decision support system, agricultural advice

\begin{abstract}
The paper presents a concept of utilising existing IT systems supporting shops supplying plant protection products to farmers in order to assist chemical protection of plants. The method implies use of sales alerts to generate messages intended for agricultural producers. The system created on this basis may supplement the existing systems signalling threats from pests. Implementation of the proposed solution does not require high financial outlay providing at the same time the possibility of reaching a large number of recipients, also at small farms. A disadvantage of the proposed solution is its lower effectiveness compared with the advanced warning systems.
\end{abstract}

\section{INTRODUCTION}

Protection of cultivated plants against pathogens is becoming an increasingly important task for the farmer. These actions are very essential in sustainable and integrated agriculture. The existing crops require using appropriate chemical agents, applied in the appropriate dose and at the appropriate time. Correct use of plant protection products requires not only extensive knowledge and skills but also access to up-to-date information (Stenberg, 2017). Lack of application of adequate protection, application of inappropriate products and doses or implementing protective measures at the wrong time may cause considerable losses to the farmer (Królczyk, et al. 2014; Niemiec, et al. 2017). These losses can include not only the loss of crops (its quantity and quality) but also damage to the plantation. Incorrectly managed plant protection may lead to the development of resistance of pests, which may cause insensitivity of pathogens to the agents used in the future (Dent, 2000; Martinez-Medina, et al. 2016).

Although the list of chemical agents authorised for use often changes, it is currently relatively easy for the farmer to acquire information on the kind of product that they should apply. Information on the dosing of preparations for particular plants is also readily available. It is significantly more difficult to determine the optimal time for carrying out the procedure. Also, farmers are not always able to correctly identify the pest that they need to combat.

Present consultancy systems supporting plant protection are focussed on providing agricultural producers with information on the potential or observed threat (Walczak, et al. 2010). The recipient obtains information on the suggested time and type of protective measures that they should apply. The functioning of such systems is based on observations of occurrences of pathogens (mainly insects and plant diseases) and on threat prediction algorithms. These algorithms, dedicated to the individual plants and pests, calculate the risk of occurrence of the particular threat based on above all weather data, such as temperature and humidity. In these systems, an alert appears when the calculated risk of pest occurrence exceeds the permissible value (Bajwa, et al., 2003; Di Guardo, 2017; Murali, et al., 1999). 
Such systems prove themselves in fruit farming (Agrosimex), they are implemented at horticultural farms as well as for selected field plants (cereals, potatoes, sugar beets) (Piorin, IUNG, Target, IOR). Availability of such information is limited to some selected areas (Nieróbca, Zaliwski, 2014).

Currently, the majority of farms in Poland do not use any warning system for pests. Small farms, which cannot or do not want to invest money in the purchase of a commercial system, apply plant protection using their own knowledge and observations of the plants they grow. This kind of approach is ineffective and may lead to the spread of pests.

\section{INPUT DATA}

Within the framework of the plant protection support system being designed, the fundamental assumption that was made concerns the possibility of taking advantage of the available data. It was assumed that the majority of farmers are currently not interested in having their data regarding their own observations of diseases and pests in plantations entered into the network. Due to the lack of time, these data will be difficult to acquire from vendors of plant protection products. However, at the time when such information will be possible to obtain, the efficiency of the system will increase substantially. These assumptions were confirmed in interviews with interested persons (farmers, vendors).

Data that can possibly be used include information on the sales of plant protection products coming from the ERP system deployed at shops in rural areas. For the research, the existing system Comarch ERP Optima was used (Comarch). This software uses the Microsoft SQL Server. Useful information can be retrieved from the database to the decision support system by means of appropriate SQL queries. Similar architecture is used by other popular programs for sales management (e.g. the Subiekt ('shop assistant') by the Insert Company).

When a threat is looming, farmers start buying appropriate plant protection products. As a rule, these products are not stocked up for later use. Thus, it can be assumed that such an increase in the sales is caused by the occurrence of a pest threat. Even though this signal comes already after the occurrence of the pest, for many farmers the information appears early enough for the losses to be prevented. It can also be observed that increased purchases appear at the time when the weather is appropriate for the sprays.

The minimum necessary scope of data that should be downloaded from the ERP system are: the date of sale, the type of plant protection product and its quantity. Additionally, due to the different sizes of packages and types of products the desirable data also include the size of the package and the unit of measurement. A good indicator can be the unit price. With the use of such data, it is possible to automatically obtain information on when sales of a particular product rises rapidly.

Fig. 1 and Fig. 2 present examples of data from two consecutive years with months marked on the horizontal axis. The data has been compiled with an accuracy of one day (the ERP Optima system can provide the hour and minute of the sale). 


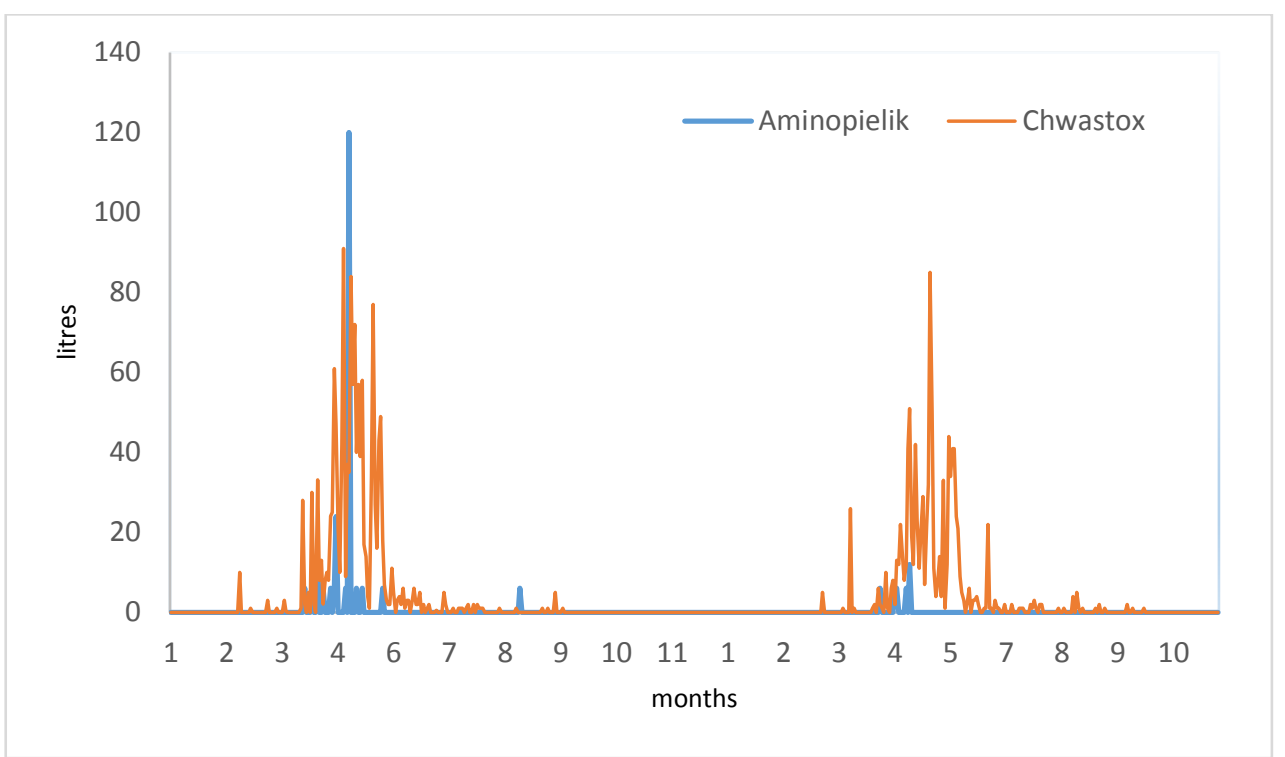

Fig. 1. Example of herbicide sales [litres]

The graphs present examples of plant protection products (herbicides: Aminopielik and Chwastox, insecticides: Actara and Decis). As of the final day of the study, the database of the shop contained 3,728 products, of which 741 were chemical agents. In order to generate alerts that signal the occurrence of pests, it is necessary to arrange the products into groups. In the database concerned, the groups of products were defined according to the sales criteria; there was no breakdown into herbicides, fungicides, insecticides, etc. For the needs of the system being created, it is thus necessary to develop an additional database containing rules for grouping products together.

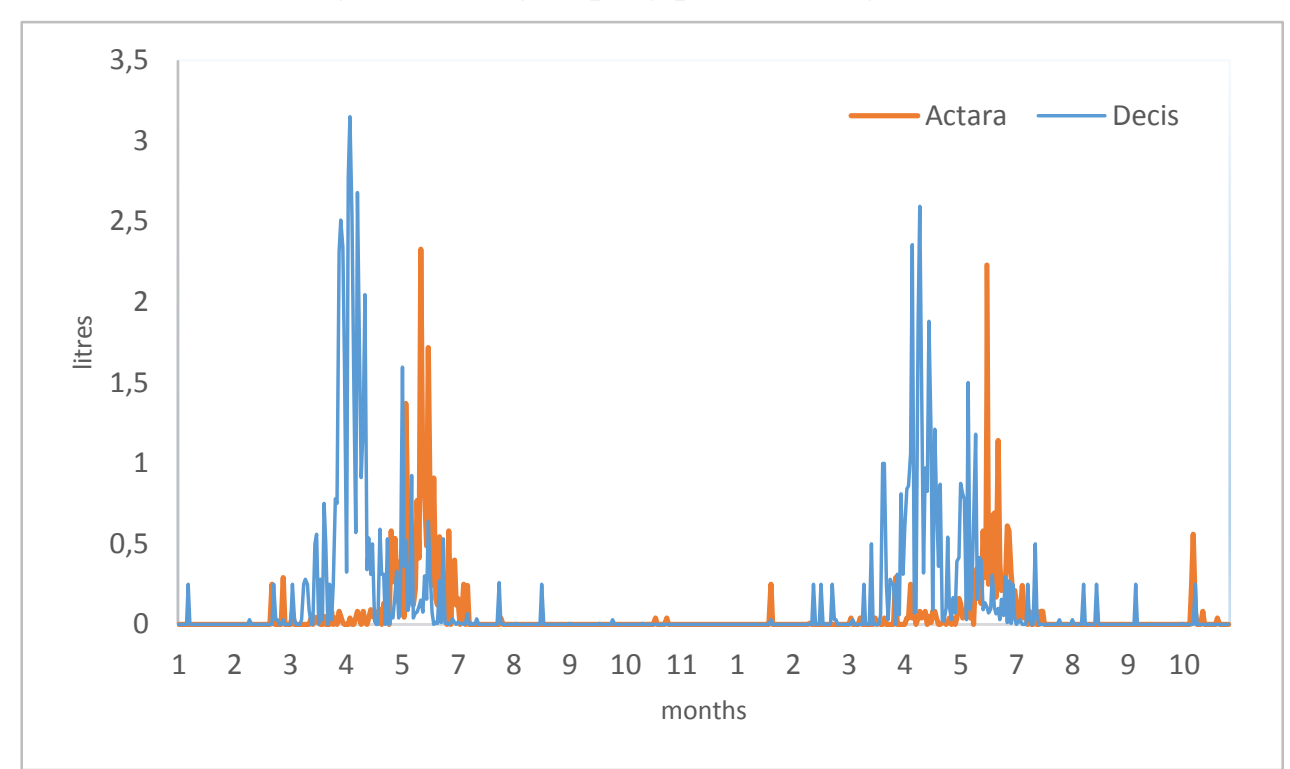

Fig. 2. Example of insecticide sales [litres]

In the graphs, the days when the sales of the particular chemical agents rises can be clearly noticed. This is visible with regard to both insecticides (Fig. 2) and herbicides (Fig. 1). These correlations occur in the successive years. Graphs illustrating the sales of other chemical agents are similar. 


\section{SYSTEM DESCRIPTION}

Fig. 3 presents a simplified scheme of the system of plant protection support. Data loaded from the SQL database of the ERP software are filtered and then the sales increase is detected.

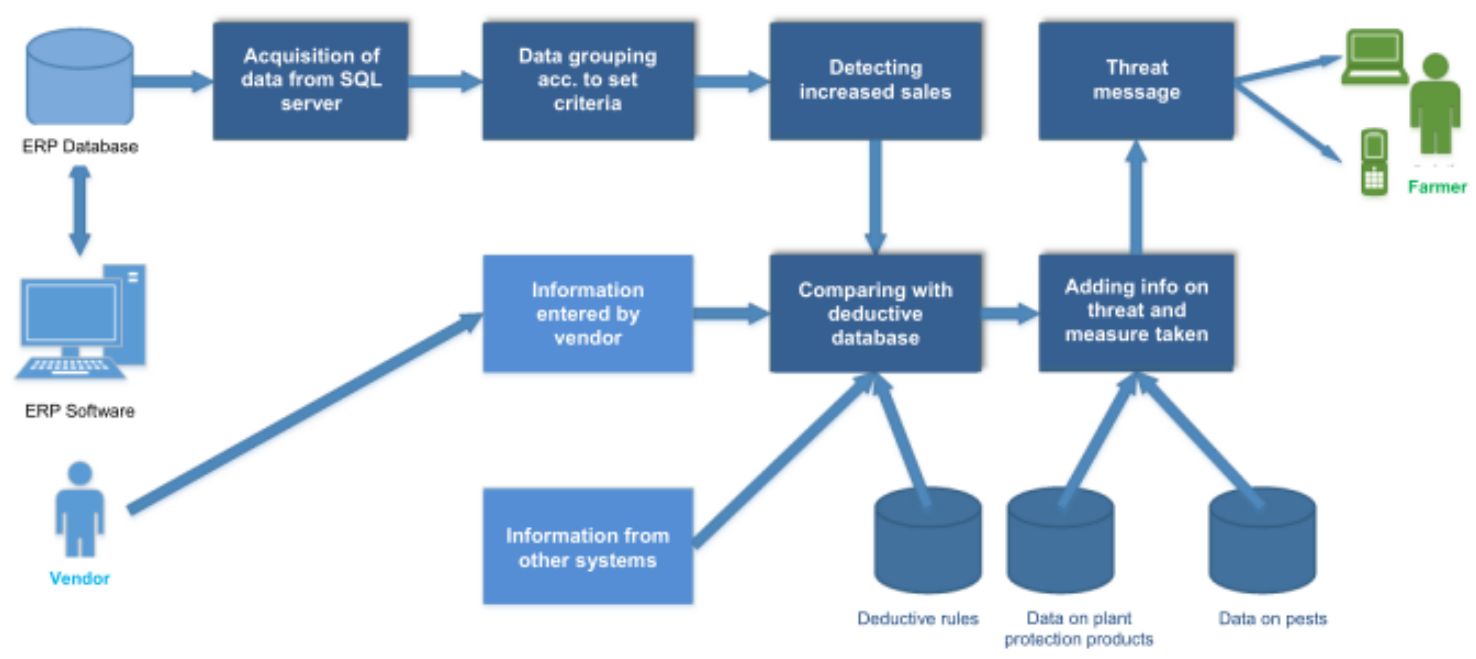

Fig.3. Simplified scheme of the system

If an increase in the sales of a particular product is detected, this information is checked using a set of deductive rules (deductive database) and then the information on the current threat and the necessity of applying an adequate chemical agent is added. An appropriately formatted message is sent to the recipient. The message can be delivered in the form of an email or a short text message, or it can be displayed on the vendor's monitor or banner, etc.

Due to the fact that the increase in the sales of selected plant protection products may be in some cases insufficient information, it is advisable to extend the system with two additional elements. The first of them is additional information entered into the system by the vendor, such as the type of threat, the type of cultivation and also the farmer's details (farmer's details can be obtained from the ERP system). This information is available to the vendors because farmers often seek advice from them. An additional functionality is integration with other alert systems (freely available or commercial). Such integration will not only increase the availability and reach of the alert systems but it will also increase their effectiveness.

In the simplest version, the system may be an application installed on the vendor's computer. In a more extended version, it might be a network application aggregating data from multiple shops and other points of sale. While the functionality of the extended version is considerably greater, there is still the risk that vendors will not make their sales statistics available due to competition concerns. Implementation of the application at a company requires acquisition of information on the structure of the ERP database as well as user authentication on the SQL server.

\section{CONCLUSIONS}

The proposed method is not intended to replace the extended consultancy systems in the scope of plant protection but to be a supplement to them. Its effectiveness does not match 
the existing solutions; however, the ease of implementation and the possibility of using available data might ensure that it will be used by a large number of farmers who do not use the existing commercial solutions. The method implies taking advantage of sales alerts to generate messages intended for agricultural producers and, in some situations, it may fail to ensure that the alert is delivered on time. This disadvantage of the system may render it useless in the view of some agricultural producers. Implementation of the proposed solution does not involve any high financial outlay; at the same time, it provides the possibility of reaching a large number of prospects, also at small farms. The system does not require entering any additional data either on the part of the vendor or the user. The effectiveness of the system can be substantially improved when information concerning the possible threats is entered by the vendor. This sort of information usually comes from farmers buying plant protection products - vendors commonly give advice to their customers. However, this requires entering additional data at the time when a greater number of customers appear in the shop. But some vendors do notice possible marketing advantages of such a solution. Integration of the proposed system with the consultancy systems already available in the market will allow achieving high effectiveness of alerts with retained availability for agricultural producers.

\section{REFERENCES}

Agrosimex. Info-Karta. Orchard messages. http://agrosimex.pl/komunikaty-sms/

Bajwa, W. I., Kogan, M., \& Center, I. P. P. (2003). Internet-based IPM informatics and decision support. https://ipmworld.umn.edu/bajwa

Comarch. ERP Optima. http://www.comarch.pl/erp/comarch-optima/

Dent, D. (2000). Insect pest management. Eastbourne. Cabi.

Di Guardo, A. (2017). Environmental decision support systems (EDSS) for risk management of chemicals in agriculture. Università degli Studi di Milano-Bicocca.

https://boa.unimib.it/bitstream/10281/158191/2/phd_unimib_787817.pdf

IOR. Platform signaling pests. http://www.agrofagi.com.pl/

IUNG. Advisory system in sustainable plant production. http://www.dss.iung.pulawy.pl/index.html

Królczyk, J. B., Latawiec, A. E., \& Kuboń, M. (2014). Sustainable agriculture - the potential to increase wheat and rapeseed yields in Poland. Polish Journal of Environmental Studies, 23(3), 663-672.

Martinez-Medina, A., Flors, V., Heil, M., Mauch-Mani, B., Pieterse, C. M., Pozo, M. J., ... \& Conrath, U. (2016). Recognizing plant defense priming. Trends in Plant Science, 21(10), 818-822.

Murali, N. S., Secher, B. J., Rydahl, P., \& Andreasen, F. M. (1999). Application of information technology in plant protection in Denmark: from vision to reality. Computers and Electronics in Agriculture, 22(2), 109-115.

Niemiec, M., Sikora, J., Szelag-Sikora, A., Kubon, M., Olech, E., \& Marczuk, A. (2017). Applicability of food industry organic waste for methane fermentation. Przemyst Chemiczny, 96(3), 685-688.

Nieróbca, A. \& Zaliwski, A. S. (2014). Expert systems as a tool for decision support in integrated pest management. Agricultural Engineering, 18.

Piorin. Internet pest signaling system. Main Inspectorate of Plant Health and Seed Inspection. https://piorin.gov.pl/sygn/start.php

Stenberg, J. A. (2017). A Conceptual Framework for Integrated Pest Management. Trends in Plant Science, 22(9), 759-769.

Target. Emergency for plants. http://www.target.com.pl/porady-i-inspiracje/pogotowie-dla-roslin/

Walczak, F., Tratwal, A. \& Krasinski, T. (2010). Kierunki rozwoju prognozowania i sygnalizacji agrofagów w ochronie roślin rolniczych. Progress in Plant Protection, 1(50). 